\title{
Noonan Syndrome: Auxological and Endocrinological Investigation
}

\author{
Kiyosato Matsuo, Kenji Nakatsuka and Yoshiharu Aoki
}

Department of Pediatrics, Yamaguchi University School of Medicine, Ube, Yamaguchi (K.M.), Department of Pediatrics, Yamaguchi National Hospital, Toyoura (K.N.), Department of Pediatrics, Nagato General Hospital, Nagato (Y.A.), Japan

\begin{abstract}
We have analyzed the auxological and endocrinological data of nine Japanese patients (5 male, 4 female) with Noonan syndrome, and have started growth hormone (GH) therapy in four patients. Eight children were short (height SD score -2.70 to -4.88 ). The growth curve for height of nine patients with this syndrome followed below normal or along $-2.0 \mathrm{SD}$ curve, and three males who attained adulthood had a tendency to delayed puberty.

The GH response to standard provocation tests done in seven patients was almost normal with normal levels of urine GH excretion, but four of seven showed low levels of plasma insulin-like growth factor-I (IGF-I). Mean concentrations of serum GH during the first three hours of sleep were normal in three patients and low in one. The discrepancy of GH and IGF-I may suggest some dysfunction of GH and IGF-I axis.

We treated four patients with GH in doses of $0.5 \mathrm{iu}$ per $\mathrm{kg}$ weight per week. Three of them showed increased height velocity, and two of these showed increased height velocity SD. One male, who started GH therapy during puberty, showed no improvement of height velocity or height velocity SD. During GH therapy one male had a convulsion, another male had arthrosis of the jaw, and one female had pains in her knee joints. However, their symptoms were all transient.

We conclude that GH therapy in Noonan syndrome is effective if started earlier than puberty, without any major side-effects.
\end{abstract}

Key words: Noonan syndrome, growth curve, IGF-I, GH therapy

\section{Introduction}

Noonan syndrome is characterized by short stature, peculiar face, webbing of the neck, cubitus valgus, pulmonary stenosis, and other

Correspondence: Dr. Kiyosato Matsuo, Department of Pediatrics, Sanyo Central Hospital, Sanyo, Yamaguchi 757 Japan anomalies (1). However, the etiology of this disease is still unknown. There have been few studies which have examined the growth hormone secretion and IGF-I in these subjects, and the response to $\mathrm{GH}$ therapy has not been well documented. We report the growth pattern of nine patients with Noonan syndrome, and their endocrinological examination and trial of GH treatment. 
MATSUO et al.

Table 1. Clinical Features of Patients with Noonan syndrome

\begin{tabular}{|c|c|c|c|c|c|c|c|c|c|}
\hline \multirow[b]{2}{*}{ no } & \multirow[b]{2}{*}{ sex } & \multirow{2}{*}{$\begin{array}{c}\text { age } \\
\text { yr mos } \\
\end{array}$} & \multicolumn{2}{|c|}{ SD score } & \multicolumn{2}{|c|}{ parent height $(\mathrm{cm})$} & \multirow{2}{*}{$\begin{array}{l}\text { heart } \\
\text { defect }\end{array}$} & \multirow{2}{*}{$\begin{array}{l}\mathrm{DQ} \\
\text { or IQ }\end{array}$} & \multirow{2}{*}{$\frac{\mathrm{BA}}{\mathrm{CA}}$} \\
\hline & & & height & weight & father & mother & & & \\
\hline 1 & $\mathrm{~m}$ & $11 y^{4}$ & -3.29 & -1.16 & 172 & $140 \#$ & - & $N$ & 0.88 \\
\hline 2 & $\mathrm{~m}$ & $14 \times 9$ & -4.88 & -2.53 & $155 \#$ & 154 & PS & $\mathbf{N}$ & 0.82 \\
\hline 3 & m & $16 y^{4}$ & -2.70 & -2.89 & 163 & 160 & PS & $N$ & 0.71 \\
\hline 4 & $\mathrm{~m}$ & $18 y$ & -3.70 & -1.81 & 162 & 150 & - & 93 & \\
\hline 5 & $\mathrm{~m}$ & $20 y$ & -3.04 & .0 .52 & 163 & 155 & Ebstein & $\mathrm{N}$ & \\
\hline 6 & f & 5 y 5 & -2.75 & -2.50 & 167 & 157 & PDA & 100 & 0.74 \\
\hline 7 & f & 8 y 0 & -4.46 & -1.88 & 170 & $145 \#$ & PDA & 75 & 1.00 \\
\hline 8 & f & $8 \times 9$ & -3.20 & -4.61 & 172 & 162 & - & $N$ & 0.66 \\
\hline 9 & f & 9 y 6 & -1.75 & -0.81 & 166 & 154 & VSD, AS D & $N$ & \\
\hline
\end{tabular}

\#: below-2.0SD, with some phenotypes of Noonan syndrome.

Subjects and Methods

Nine Japanese patients (five male and four female) with Noonan syndrome were enrolled in this study. Their ages at the examination ranged from 5 years 5 months to 20 years. All examinations and therapies were done after parental informed consent had been obtained. Growth curves of these patients were drawn with their health records available. Bone age was evaluated by Greulish and Pyle's atlas. After confirming normal thyroid function, GH secretion was assessed in seven patients with insulin $(0.1 \mathrm{unit} / \mathrm{kg}$ iv), l-arginine $(0.5 \mathrm{~g} / \mathrm{kg} \mathrm{div}), 1$-dopa $(10 \mathrm{mg} / \mathrm{kg} \mathrm{po})$, or clonidine $\left(100 \mu \mathrm{g} / \mathrm{m}^{2}\right.$ po) loading tests, and by the mean $\mathrm{GH}$ concentration during the first three hours of sleep and urinary excretion of $\mathrm{GH}$ in the first voided morning urine. Growth hormone treatment was started in four patients (two male and two female) with doses of $0.5 \mathrm{iu} / \mathrm{kg} /$ week. The period of $\mathrm{GH}$ treatment was from 12 months to 36 months.

\section{Results}

Table 1 shows the clinical data of the nine patients. Their ages at the evaluation ranged from 5 years 5 months to 20 years. The height SD score was $-1.75 \mathrm{SD}$ to $-4.88 \mathrm{SD}$, weight SD score $-0.52 S D$ to $-4.61 S D$. Six out of nine had a congenital heart defect, and of these two had pulmonary stenosis, two had PDA, one had Ebstein anomaly, and one VSD and ASD. Three of them had had heart surgery long before this assessment; the others had not need surgery. The reported height of their parents was below $-2.0 \mathrm{SD}$ in three cases, and they had some phenotypes of Noonan syndrome such as short neck, skin nevi, and shield chest. The bone age was retarded in five out of six patients examined.

Figure 1 illustrates the height curve of these patients. Their curves followed below or along the $-2.0 \mathrm{SD}$ curve. Three male patients (nos.2, 3, 4) who attained adulthood had a tendency to delayed puberty. The dotted line in the curves of nos.1, 2, 6, and 8 indicates the period of $\mathrm{GH}$ therapy.

Endocrinological evaluation was done in 

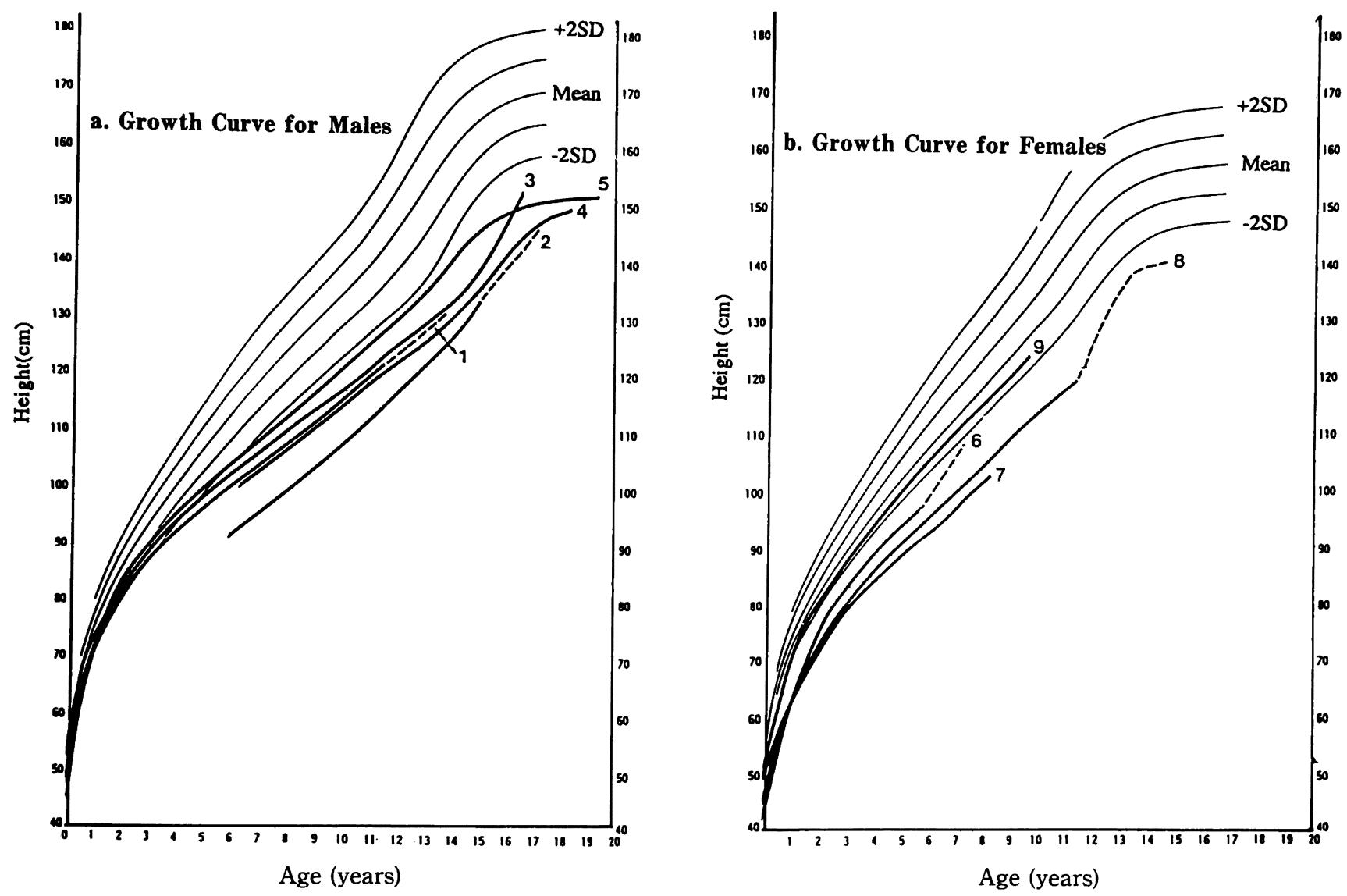

Fig. 1. Growth curves of male (a) and female (b) patients with Noonan syndrome. Dotted lines show the period of GH therapy. The number of the line corresponds to that of table 1.

seven subjects. As shown in Table $2 \mathrm{GH}$ responses were almost normal, though peak GH values of patients no.2 and no.8 were relatively low in some provocation tests. Mean GH concentration of sleep was normal in no.1, no.2, and no.8, but low in no.6. Urine excretion of GH was low normal in five. Plasma IGF-I level was low in four but normal in two. There is a discrepancy between GH secretion and IGF-I.

The changes of height velocity and height velocity $\mathrm{SD}$ score before and after $\mathrm{GH}$ therapy are shown in Figure 2. Height SD increased in no. 2 , no. 6 and no. 8 after 12 months of therapy, but decreased in no. 8 thereafter. That of no.1 decreased in spite of $\mathrm{GH}$ therapy. Height velocity SD score, which is calculated as the scale of bone age, turned upward in no. 6 and no.8, but downward in no.1 and no.2.

\section{Discussion}

Growth curves of these Japanese patients with Noonan syndrome are similar to those in reports from Canada (2) and West Germany (3) in that the curves remain at the lower end of normal range. The growth spurt indicating puberty was delayed by about two years in our subjects, as in the German patients. Total increment of height during puberty was relatively small compared to normal people. Our data suggest that their adult height reached around or below $-2.0 \mathrm{SD}$. Normal GH responses to provocation tests and lower levels of urine GH and plasma IGF-I may represent impaired spontaneous secretion of $\mathrm{GH}$, or dysfunction in the hypothalamo-pituitary GH and IGF-I axis. 
MATSUO et al.

Table 2. Endocrinological data

\begin{tabular}{|c|c|c|c|c|c|c|c|}
\hline \multirow[b]{2}{*}{ no } & \multirow{2}{*}{$\begin{array}{c}\text { IGF-I } \\
\mathrm{U} / \mathrm{ml}\end{array}$} & \multicolumn{4}{|c|}{ peak $\mathrm{GH}^{*}$ level tested with } & \multirow{2}{*}{$\begin{array}{c}\text { mean } \\
\text { sleep } \mathrm{GH}^{*}\end{array}$} & \multirow{2}{*}{$\begin{array}{l}\text { urine } \\
\text { GH\# }\end{array}$} \\
\hline & & insulir & clonidin & 1-Arg & 1-dopa & & \\
\hline 1 & 0.39 & & 25 & & 11 & 7.36 & 11.8 \\
\hline 2 & 0.47 & 5.3 & 22 & 14 & & 9.6 & 15.0 \\
\hline 3 & 0.50 & & 15 & & & & \\
\hline 4 & & 16.0 & & 10.5 & & & \\
\hline 6 & 0.52 & 14 & 21 & 26 & 9.5 & 3.68 & 10.7 \\
\hline 7 & 1.01 & 13 & 14 & & 7.6 & & 24.9 \\
\hline 8 & 1.17 & 8.3 & 5.6 & 14.5 & 6.3 & 8.0 & 14.1 \\
\hline
\end{tabular}

$*:$ unit $=\mathrm{ng} / \mathrm{ml}, \quad \#:$ unit $=\mathrm{pg} / \mathrm{mg}$ creatinine
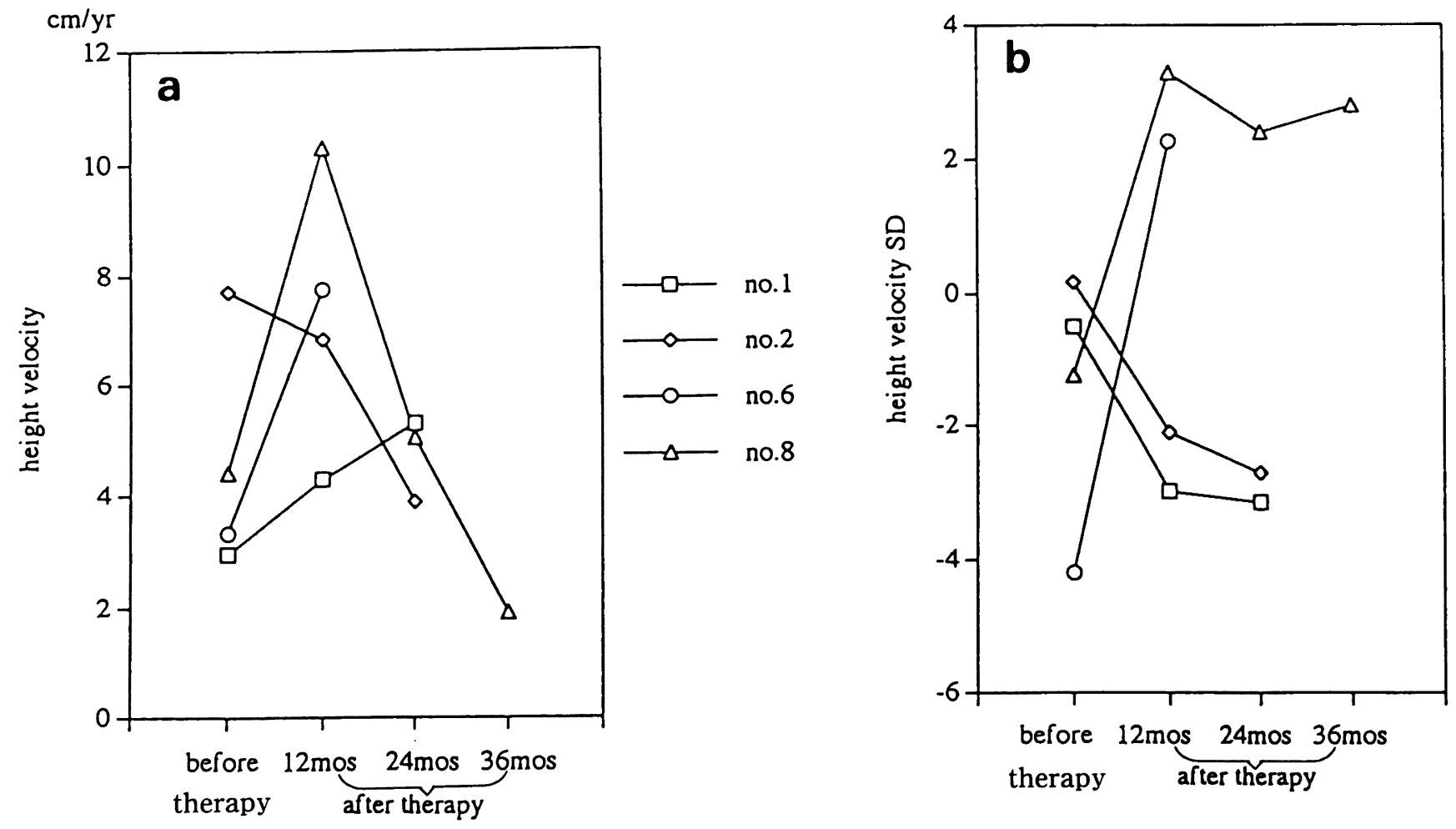

Fig. 2. Changes of Height velocity (a) and Height velocity SD score (b) before and after GH therapy. 
According to a report from England there was good response to $\mathrm{GH}$ treatment in five patients with a dose of $0.6 \mathrm{iu} / \mathrm{kg} /$ week for one year (4). Although the effect of GH therapy was not seen in all the patients enrolled in our trial, we think it was partly because the therapy was started shortly before or after the onset of puberty. Patients who started at a younger age showed increased height velocity. This means that GH therapy should be started in the earlier years.

As our patients had some side-effects during GH treatment, all of which transient, careful monitoring is necessary during $\mathrm{GH}$ therapy in patients with Noonan syndrome. It is said that some patients with this syndrome occasionally show an abnormality of electroencephalographm, although we did not check this in our patients unless they had a convulsion.

We cannot predict the final height of patients after GH therapy with our small number of cases. A large-scale survey with $\mathrm{GH}$ treatment is necessary to assess its effect in this syndrome.

\section{References}

1. Jones KL. Smith's Recognizable Patterns of Human Malformation. 4th. ed. Philadelphia: WB Saunders, 1988: 108-9.

2. Witt DR, Keena BA, Hall JG, Allanson JE. Growth curves for height in Noonan syndrome. Clinical Genetics, 1986; 30: 150-3.

3. Ranke MB, Heidemann P, Knupfer C, Enders H, Svhmaltz, Bierich JR. Noonan syndrome: growth and clinical manifestations in 144 cases. Eur J Pediatr, 1988: 220-7.

4. Ahmed ML, Foot ABM, Edge JA, Lamkin VA, Savage MO, Dunger DB. Noonan syndrome: Abnormalities of the growth hormone/IGF-I axis and the response to treatment with human biosynthetic growth hormone. Acta Paediatr Scand, 1991; 80: 446-50. 